\title{
WHAT DRIVES OUR PROJECT TEAMS?
}

\author{
Annett Schöttle ${ }^{1}$
}

\begin{abstract}
Motivation drives our behavior that leads to performance and achievement of targets. Especially in collaborative delivery systems, the motivation within a group is sensitive to the project conditions and relationships within the team. However, research on motivation is underrepresented in construction and is mainly based on the simplified classification into intrinsic and extrinsic motivation. This concept is obsolete. In recent decades the selfdetermination theory (SDT) developed by Deci and Ryan has spread within the motivation and organizational theory. SDT defines motivation based on the three psychological needs, (1) autonomy, (2) competence, and (3) relatedness, and divides extrinsic motivation according to the degree of autonomy. Since the theory has not been transferred to the construction industry, this paper applies existing scales to give - based on a particular case - a first indication regarding the following question: What drives project team members in the construction industry? Therefore, one year after 21 interviews with one project team were conducted, a survey was sent to the interviewees (90\% response rate), now working on different projects in different project teams. It was found that autonomous motivation drives the selected participants. Furthermore, the data shows that good relationships as well as the feeling of competence regarding their task are important and need to be considered when developing the project settings.
\end{abstract}

\section{KEYWORDS}

Collaboration, Lean construction, motivation, psychological needs, self-determination theory.

\section{INTRODUCTION}

Within the Lean community it is often argued that collaboration is key for project success, but a lack of knowledge exists regarding the motivation of the team reflected in their willingness to collaborate. Collaboration evolves over time and requires "a common vision to create a common project organization with $[\ldots]$ a new and jointly developed project culture, based on trust" (Schöttle et al. 2014, p. 1275). The definition clearly shows the importance of the human factor within the project delivery system. The behavior of project team members is impacted by their motivation. Thus, motivation is the driver of behavior, the driver that leads to performance and achievement of targets. Especially with collaborative delivery systems such as Integrated Project Delivery (IPD), the motivation within a group is sensitive to the conditions of the project and relationships within the project team. However, motivation research in construction is underrepresented and mainly based on the simplified classification into intrinsic and

1 Senior Consultant, Refine Projects AG, Schelmenwasenstraße 34, 70567 Stuttgart, Germany, +4915156561529, annett.schoettle@,refine.team and Founder and Co-Director, CollabDecisions, www.collabdecisions.com, orcid.org/0000-0001-6001-7320 
extrinsic motivation (e.g., Christensen et al. 2019). This concept is obsolete. In recent decades the self-determination theory (SDT) developed by Deci and Ryan (e.g., Deci and Ryan 1985; Deci et al. 2017) has diffused the motivation and organizational theory. SDT defines motivation based on the three psychological needs, (1) autonomy, (2) competence, and (3) relatedness, and divides extrinsic motivation according to the degree of autonomy, because the theory understands "human beings are active, growth-oriented organisms who are naturally inclined toward integration of their psychic elements into a unified sense of self and integration of themselves into larger social structures" (Deci and Ryan 2000, p. 229).

Therefore, the aim of the paper is to better understand what the project team needs in order to collaborate. Thus, this paper will make a first attempt for the construction industry to answer the question: What drives project team members in the construction industry? To answer the question, first the SDT will be introduced. Then the research method will be explained, and the collected data analyzed. Findings will be discussed and in the last section the conclusion will be drawn by reflecting on the limitations of this study.

\section{SELF-DETERMINATION THEORY}

Deci and Ryan (1985) examined the question of what happens when an intrinsically motivated activity is compensated by an extrinsic incentive. Based on various experiments, field tests, and investigations, the authors concluded that financial incentives, a potential punishment for non-fulfillment, deadlines, negative feedback, and the knowledge of control can impair the intrinsic motivation, resulting in a possible loss of performance (Deci and Ryan 1985; Gagné and Deci 2005). The loss of performance can be explained by the dependence of the reward on an activity and the accompanying change of the perceived locus of causality from internal to external (Deci and Ryan 1985). Nevertheless, financial incentives can and do have a positive impact if they are considered as informative and not as a controlled instrument. Moreover, they are perceived as having a positive impact on motivation if they are not the norm and not expected by the recipient (Deci and Ryan 1985), because the expectation itself can result in disappointment if the financial incentive is not paid (Deci and Ryan 2000; Fehr and Falk 2002). Thus, motivation is complex, and when implementing incentives different aspects need to be considered.

SDT criticizes the simple distinction between extrinsic and intrinsic motivation and argues that the extrinsic motivation is characterized by the degree of autonomy (Deci and Ryan 2000), and thus involves control. Extrinsic motivation is therefore classified into four further categories: (1) external, (2) introjected, (3) identified, and (4) integrated regulation. External regulation is based on the use of external rewards and punishments, so that individuals feel forced to act in a certain way. Ego is involved in the introjected regulation by focusing on approval from self or others through performance. Individuals engage because of pride, shame or guilt. Identified regulation means that the individual identifies themselves with the goals and values of the action. If the individual fully assimilated the identified regulation, integrated regulation occurs (Ryan and Deci 2000a). Here, goals, values, and regulations are congruent with the individual's goals and values. External and introjected motivation is always controlled. In contrast, intrinsic motivation is always autonomous (e.g., Deci et al. 2017; Gagné et al. 2015; Gagné and Deci 2005; Ryan and Deci 2000a). 
Figure 1 illustrates the self-determination continuum. Thus, to increase the performance of a project team the autonomous motivation needs to be triggered. The key of autonomous motivation is based on the satisfaction of the three psychological needs: (1) autonomy (psychological freedom and choice), (2) competence (feeling of effectivity), and (3) relatedness (building and maintaining trustful relationships) (e.g., Broeck et al. 2010; Deci and Ryan 2014; Ryan and Deci 2018). While all three needs are positively related to autonomous motivation, "only autonomy satisfaction [is] related negatively to controlled motivation” (Broeck et al. 2010, p. 995). In other words, instead of focusing on financial incentives, an environment should be developed that promotes autonomous activities and hence favors intrinsic motivation (Broeck et al. 2010; Deci et al. 1981; Ryan and Deci 2000a; b).

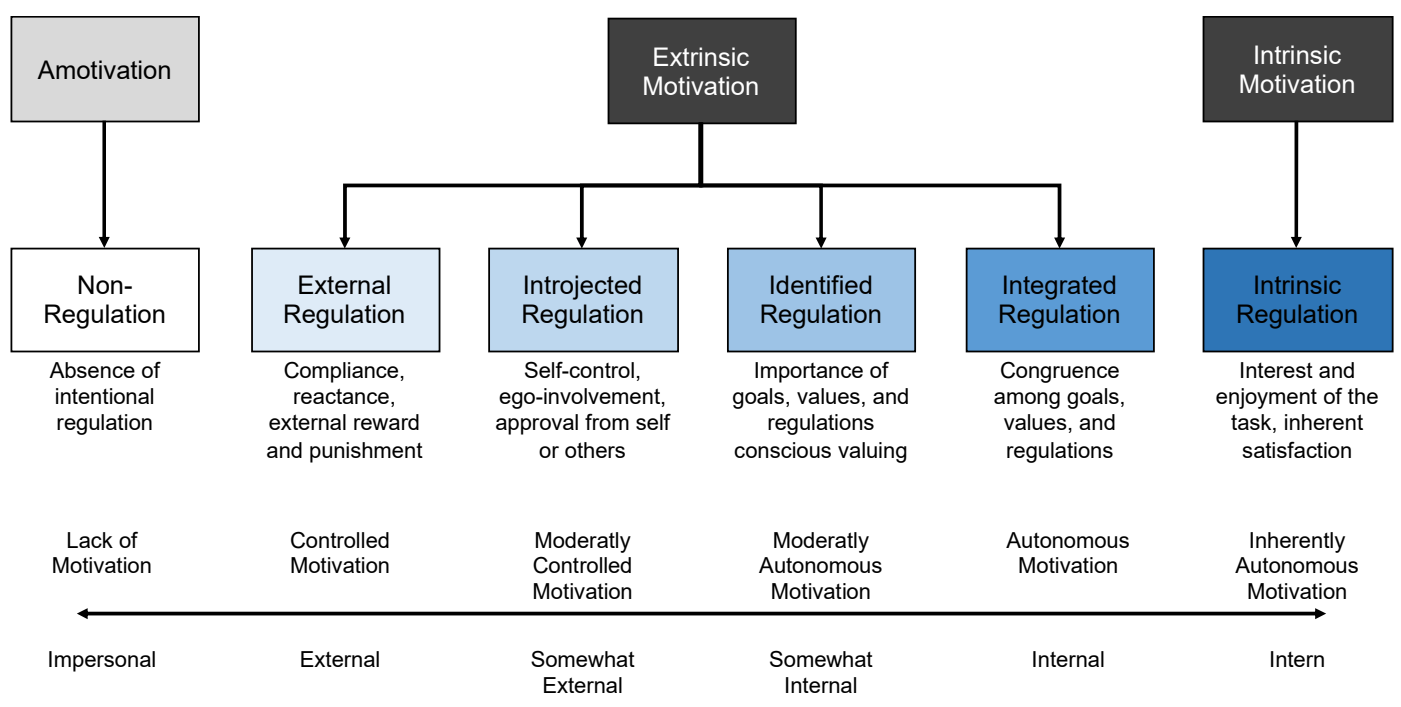

Figure 1: The self-determination continuum (Ryan and Deci 2000a, b)

\section{RESEARCH METHOD}

The author used a specific case to analyze the fulfillment of psychological needs and thus the degree of autonomy of a project team to answer the defined research question. The selected group experienced Lean within the design and construction phase in the same project for the first time. After the handover of the building, those team members were successively spread out to other projects in Germany and Austria in January 2019. At the same time, 21 interviews were conducted amongst others regarding the implemented production system, decision-making, and collaboration about the BMW Freimann project (Schöttle and Nesensohn 2019). These interviews showed the importance of a production system that is based on product request and the project team's needs, and serves as a reference point to discover the motivation of the selected group. Thus, one year after the interviews, a survey was sent to 20 of these interviewees (one person could not be reached) to better understand the project team's motivation and needs. Four of the survey respondents are participants form the design team (architect, structural, mechanical \& plumbing, and electrical engineer) and 14 are from the construction team (project manager, construction manager and foremen from the general contractor and main trades). Team members were now assigned to new projects, thus working in new teams. These multiple projects will be named 'current project' in the following sections. The 
survey is based on existing SDT validation measures that were scientifically developed and applied to SDT in different work environments such as universities, the military, human resource companies, or call centers. Thus, the survey consists of the following parts:

- Work-related Basic Need Satisfaction scale (W-BNS) to measure work-related need satisfaction (Broeck et al. 2010).

- Work Extrinsic and Intrinsic Motivation Scale (WEIMS) to measure work motivation based on self-determination theory (Tremblay et al. 2009).

- Multidimensional Work Motivation Scale (MWMS) to measure "work motivation at the domain level of analysis" (Gagné et al. 2015, S. 179).

- Additional questions regarding the current project situation and personal data.

The MWMS varies from the WEIMS in two areas. First, it does not include integrated regulation, because statistically it does not demonstrate a variance regarding the outcome and it is difficult to differentiate between identified regulation and intrinsic motivation (Gagné et al. 2015). Second, MWMS differs by separating external regulation into material and social rewards (Gagné et al. 2015). Although MWMS is a further development of previous scales such as WEIMS, for the purpose of this paper both scales can be used, because the paper provides a first impression regarding the use of the SDT in construction and is limited to a small sample.

The evaluation of the questions is based on 5-point Likert scales ranging from 1 (totally disagree) to 5 (totally agree). The questions were translated by the author and aligned regarding the current and the past project (reference project BMW Freimann). First, questions were asked about the current project to minimize the anchoring effect (bias regarding reference point). Then, the same questions were asked regarding the BMW Freimann project. Eighteen people completed the survey ( $90 \%$ response rate).

\section{DATA ANALYSIS}

\section{Reference and Current Project}

The reference project is an office building in which all survey participants were involved either in the design phase or in the construction phase. The project was finished on time and within budget and is characterized as a fast track project with an overlapping design and construction phase. Last Planner ${ }^{\circledR}$ System (LPS) was implemented as the production system from the detailed design phase throughout handover and commissioning. During the construction phase a takt was integrated into the LPS for repeatable areas. Lean and the LPS were new to all project participants as well as to their organizations (Schöttle and Nesensohn 2019). Based on interviews, observations, and workshops, Schöttle and Nesensohn (2019) found that a phase-overlapping production system such as the LPS can help to create a collaborative environment. Based on the first data, the project can be characterized as a collaborative working environment with strong relationships among the project team. This outcome is in line with the survey response.

Participants were asked to name a word that came directly into their mind when asked how they feel about the reference as well as the current project (see Table 1). The data shows that the reference project is very positively anchored in the respondents' minds. In comparison, $50 \%$ of the respondents named negative feelings and moods regarding their current project. LPS was implemented in the reference project. All survey participants 
were trained in LPS, involved in the milestone and phase scheduling, and participated in the weekly LPS meetings. Therefore, they were asked whether LPS was also implemented in the current project. In 50\% of the projects, LPS was not implemented among the project team $^{2}$. The combination of both questions clearly shows that LPS implementation alone is not sufficient to achieve satisfaction. As expected, the topic is more complex and needs further investigation. Furthermore, according to Gagné et al. (2015), "the presence and absence of positive events, such as experiencing need satisfaction, are more associated with intense experience of positive outcomes, while the presence and absence of negative events, such as, [...], frustration, are more associated with intense experience of negative outcomes. That is, positive and negative events are not simply opposite ends of a spectrum" (p. 1221). This means that positive and negative events do not compensate each other, and this has to be considered when reflecting on the satisfaction of psychological needs.

Table 1: Feeling regarding the current and the previous project

\begin{tabular}{cccc}
\hline$\#$ & $\begin{array}{c}\text { LPS implementation } \\
\text { in the current } \\
\text { project? }\end{array}$ & $\begin{array}{c}\text { How do you feel } \\
\text { about your current } \\
\text { project? }\end{array}$ & $\begin{array}{c}\text { How do you feel about the project } \\
\text { BMW Freimann? }\end{array}$ \\
\hline 1 & No & Tough & Together \\
2 & Yes & Interesting & Respect, good time \\
Involved \\
3 & Yes & Involved & Concern about Revit \\
4 & No & Dew Tasks & Great teamwork, fun and stressful \\
5 & Yes & Satisfaction & Great \\
6 & No & Chaotic & Structure \\
7 & No & Anger & Proud and Happy \\
8 & Yes & Chaotic & Satisfaction \\
9 & No & Well planned & Teamwork \\
10 & No & Proud & Pleasure \\
11 & Yes & Motivated & Successful \\
12 & Yes & Good team spirit & Again please \\
13 & No & Mixed feelings & Super \\
14 & Yes & Assistant & Satisfaction \\
15 & No & Well... & Proud \\
16 & Only design phase & - & Satisfaction \\
17 & - & - & Solution-oriented, great team members \\
18 & - & &
\end{tabular}

Figure 2 shows the evaluation of the current situation of the different projects based on the four questions: (1) The project meets the deadlines. (2) Commitments are mostly met. (3) The potential for conflict between the team members in the project is very low. (4) I have no conflicts with other team members in the project. Combining those questions, the range spans from 4 (totally disagree) to 20 (totally agree). Two of the 18 participants where not assigned to a new project teams when the survey was carried out and therefore excluded for these questions. Most respondents evaluate their projects in the upper part of the diagram (11 out of 16), which means that their project is on track. The five

\footnotetext{
${ }^{2}$ This does not mean that participants used it for their own work or in silo. Rather, it means that there was no procedure or support to implement LPS across the project team.
} 
respondents who evaluated their projects below average $(1,3,5,7,8)$ also have clear negative feelings $(1,5,7,8)$ regarding the project. In comparison, respondents who evaluated their project with very low conflict potential and on time, have positive feelings regarding the project. Thus, it can be stated that the project environment impacts the feelings of the project team members. The data also shows that the implementation of LPS without the appropriate mindset is not working.

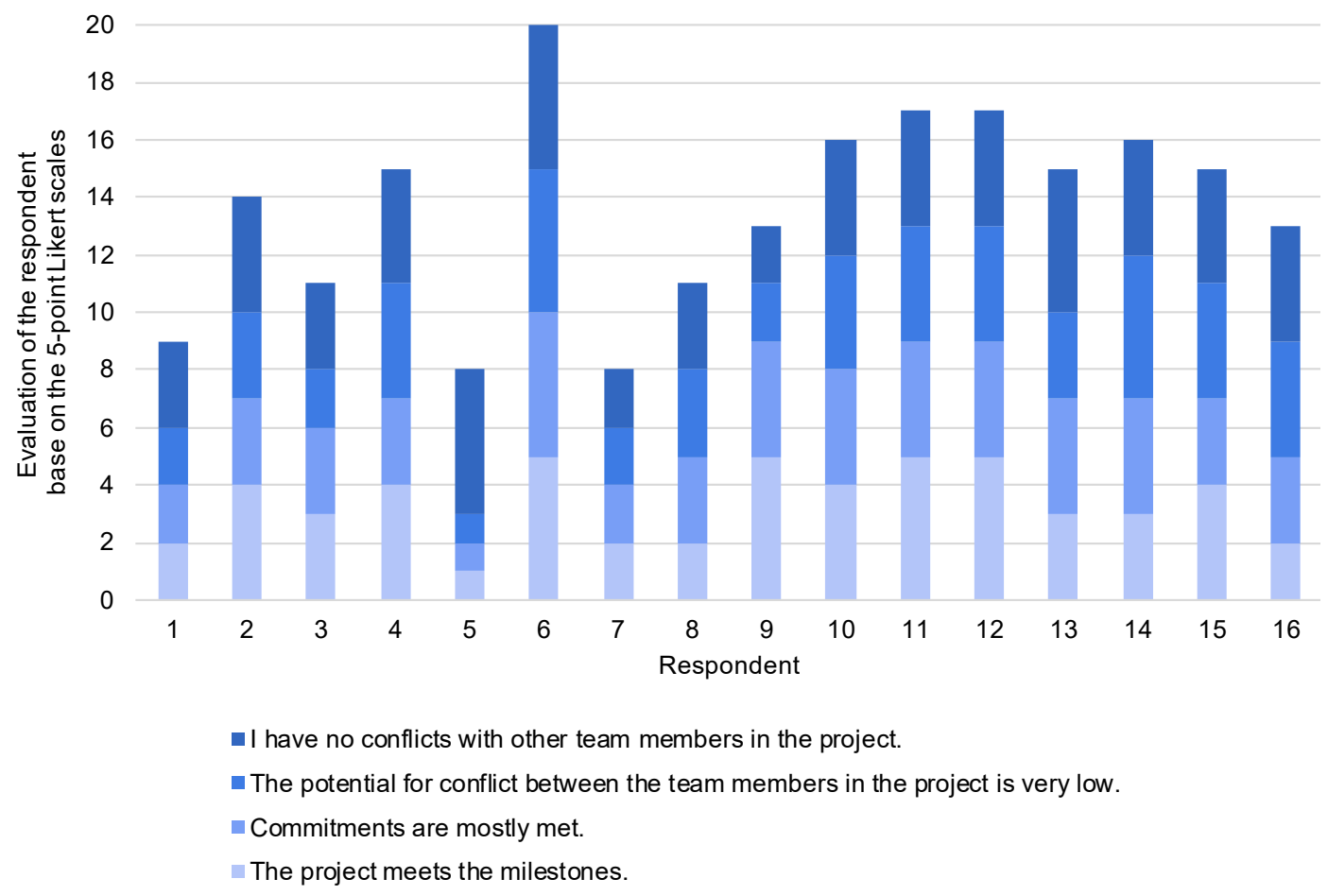

Figure 2: Evaluation of the current project situation

\section{Work-Related BaSic NeEd SATiSfaction Scale (W-BNS)}

The satisfaction of the three psychological needs - (1) autonomy, (2) competence, and (3) relatedness - is positively related to job satisfaction, and thus positively related to commitment and performance (Broeck et al. 2010). Therefore, the W-BNS scale was used to measure the three psychological needs based on the reference project and the respondents' current projects. The scale consists of six items for autonomy, four items for competence, and six items for relatedness. Figure 3 represents the means of the W-BNS scale for the case. It can be seen that the fulfillment of autonomy is a bit higher in the reference project, but nevertheless the respondents feel autonomy in both projects. Furthermore, there is no big difference regarding the need for competence between the current and the reference project. Regarding the need for relatedness, it is obvious that this need is more fulfilled in the reference project than in the current project. This is especially clear in the difference in building close friendships at work (almost 1.0). Again, reflecting the current project situation of having conflicts with other team members (Figure 2), the data is consistent. The satisfaction of the need for autonomy is on average higher in the reference project as compared to the current project. 


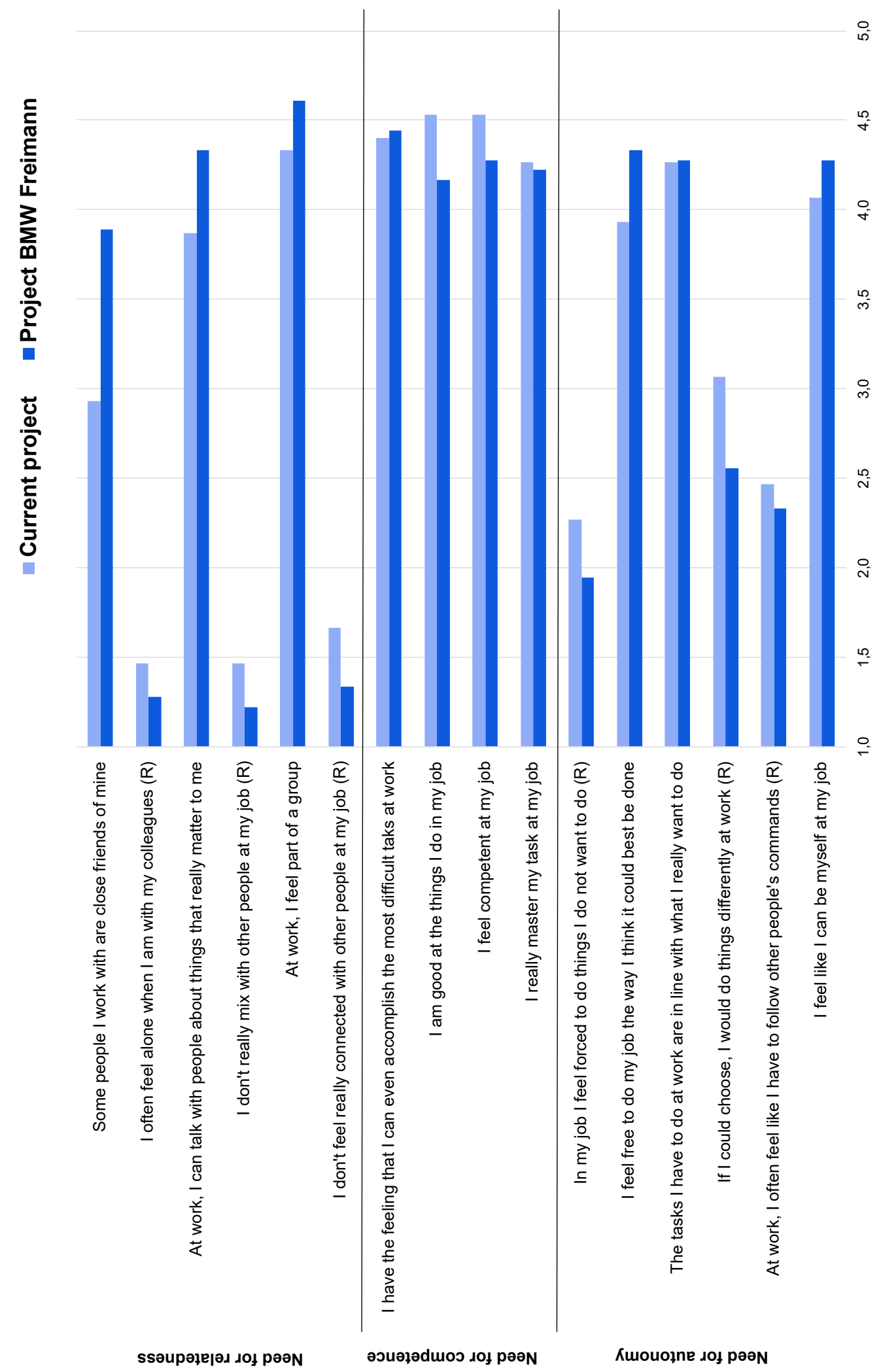

Figure 3: Mean of W-BNS ( $\mathrm{R}$ = reversed item) developed by Broeck et al. (2010) 


\section{WORK MOTIVATION}

\section{Work Extrinsic and Intrinsic Motivation Scale (WEIMS)}

To measure the work motivation based on the SDT, the WEIMS was used. Every category of the continuum contained three questions (intrinsic motivation (Intrin) 4, 8, 15; integrated regulation (Integ) 5, 10, 18; identified regulation (Ident) 1, 7, 14; introjected regulation (Introj) 6, 11, 13; external regulation (Ext) 2, 9, 16; amotivation (AM) 3, 12, 17). The numbers demonstrate the sequence of the questions in the survey. The data clearly shows that the respondents are autonomously motivated. Questions regarding amotivation have low means (see Table 2). External regulations which are based on rewards and punishments are not motivating the respondents. Questions regarding introjected regulation show more diversity. Participants want to succeed in the project (11, 6). Failing is strongly linked to disappointment and shame, which is in line with the theory where self-worth is contingent on performance. The standard deviation (SD) shows low variation within the respondents' answers. Overall, the data suggests that a high degree of autonomy is key for the participants.

Table 2: Mean (M) and standard deviation (SD) of WEIMS

\begin{tabular}{|c|c|c|c|}
\hline Regulation & $\begin{array}{l}\text { To what extent do each of the following items correspond to the } \\
\text { reasons why you are presently involved in your work? }\end{array}$ & M & SD \\
\hline AM & $\begin{array}{l}\text { I ask myself this question, I don't seem to be able to manage the } \\
\text { important tasks related to this work. (3) }\end{array}$ & 1.47 & 0.72 \\
\hline AM & $\begin{array}{l}\text { I don't know why, we are provided with unrealistic working } \\
\text { conditions. (12) }\end{array}$ & 1.59 & 0.80 \\
\hline AM & I don't know, too much is expected of us. (17) & 2.41 & 1.12 \\
\hline Ext & For the income it provides me. (2) & 3.29 & 1.10 \\
\hline Ext & Because it allows me to earn money. (9) & 3.35 & 1.17 \\
\hline Ext & Because this type of work provides me with security. (16) & 3.53 & 0.72 \\
\hline Introj & $\begin{array}{c}\text { Because I want to succeed at this job, if not I would be very } \\
\text { ashamed of myself. (6) }\end{array}$ & 4.35 & 0.61 \\
\hline Introj & $\begin{array}{c}\text { Because I want to be very good at this work, otherwise I would be } \\
\text { very disappointed. (11) }\end{array}$ & 4.24 & 0.75 \\
\hline Introj & Because I want to be a "winner" in life. (13) & 3.00 & 0.79 \\
\hline Ident & Because I chose this type of work to attain my career goals. (7) & 4.12 & 0.99 \\
\hline Ident & $\begin{array}{l}\text { Because it is the type of work I have chosen to attain certain } \\
\text { important objectives. (14) }\end{array}$ & 3.82 & 0.73 \\
\hline Ident & $\begin{array}{c}\text { Because this is the type of work I chose to do to attain a certain } \\
\text { lifestyle. (1) }\end{array}$ & 3.29 & 1.05 \\
\hline Integ & Because it has become a fundamental part of who I am. (5) & 4.35 & 0.93 \\
\hline Integ & $\begin{array}{l}\text { Because it is part of the way in which I have chosen to live my life. } \\
\text { (10) }\end{array}$ & 3.65 & 1.17 \\
\hline Integ & Because this job is a part of my life. (18) & 4.00 & 1.00 \\
\hline Intrin & Because I derive much pleasure from learning new things. (4) & 4.35 & 0.79 \\
\hline Intrin & $\begin{array}{c}\begin{array}{c}\text { For the satisfaction I experience from taking on interesting } \\
\text { challenges. (8) }\end{array}\end{array}$ & 4.59 & 0.51 \\
\hline Intrin & $\begin{array}{c}\text { For the satisfaction I experience when I am successful at doing } \\
\text { difficult tasks. (15) }\end{array}$ & 4.53 & 0.51 \\
\hline
\end{tabular}




\section{Multidimensional Work Motivation Scale (MWMS)}

Another scale to measure the work motivation based on the SDT is the MWMS. This part of the survey contained 19 questions (three to four questions per category). In accordance with the WEIMS, the data also shows the strong autonomous motivation of the survey participants (see Table 3). In line with this is the non-motivation of controlling regulations. Thus, Amotivation (AM) and Extrinsic regulation-material (Ext-Mat) do not drive the motivation of the survey participants. In comparison to the Ext-Mat $(\mathrm{M}=2.176)$, social aspects are more important (Extrinsic regulation-social (Ext-Soc) M=3.020). Furthermore, the Ext-Soc and Introjected regulation (Introj) do matter somewhat, but most important is the Identified regulation (Ident) and the Intrinsic motivation (Intrin). Furthermore, participants do not feel restricted in losing their jobs if they do not put enough effort in it. This could be another indicator for autonomous motivation or an effect of the current economically situation (high demand). Based on the data, it can be suggested that, when implementing incentives, the system should focus on the social aspects and on competence, because acknowledgement from others and self-approval matter to the respondents.

Table 3: Mean (M) and standard deviation (SD) of MWMS

\begin{tabular}{|c|c|c|c|}
\hline Regulation & Why do you or would you put efforts into your current job? & M & SD \\
\hline Am1 & I don't, because I really feel that I'm wasting my time at work. & 1.18 & 0.39 \\
\hline Am2 & $\begin{array}{l}\text { I do little because I don't think this work is worth putting efforts } \\
\text { into. }\end{array}$ & 1.12 & 0.33 \\
\hline Am3 & I don’t know why l'm doing this job, it's pointless work. & 1.29 & 0.59 \\
\hline Ext-Mat1 & $\begin{array}{l}\text { Because others will reward me financially only if I put enough } \\
\text { effort in my job. }\end{array}$ & 2.35 & 1.17 \\
\hline Ext-Mat2 & $\begin{array}{l}\text { Because others offer me greater job security if I put enough } \\
\text { effort in my job. }\end{array}$ & 2.24 & 0.75 \\
\hline Ext-Mat3 & Because I risk losing my job if I don't put enough effort in it. & 1.94 & 0.75 \\
\hline Ext-Soc1 & To get others' approval. & 3.24 & 0.75 \\
\hline Ext-Soc2 & Because others will respect me more. & 3.41 & 1.12 \\
\hline Ext-Soc3 & To avoid being criticized by others. & 2.41 & 1.18 \\
\hline Introj1 & Because I have to prove to myself that I can. & 3.71 & 1.16 \\
\hline Introj2 & Because it makes me feel proud of myself. & 3.76 & 0.97 \\
\hline Introj3 & Because otherwise I will feel ashamed of myself. & 3.18 & 1.42 \\
\hline Introj4 & Because otherwise I will feel bad about myself. & 3.65 & 1.22 \\
\hline Ident1 & $\begin{array}{l}\text { Because I personally consider it important to put efforts in this } \\
\text { job. }\end{array}$ & 4.47 & 0.51 \\
\hline Ident2 & $\begin{array}{c}\text { Because putting efforts in this job aligns with my personal } \\
\text { values. }\end{array}$ & 4.76 & 0.44 \\
\hline Ident3 & $\begin{array}{l}\text { Because putting efforts in this job has personal significance to } \\
\text { me. }\end{array}$ & 4.41 & 0.51 \\
\hline Intrin1 & Because I have fun doing my job. & 4.41 & 0.94 \\
\hline Intrin2 & Because what I do in my work is exciting. & 4.24 & 0.56 \\
\hline Intrin3 & Because the work I do is interesting. & 4.71 & 0.59 \\
\hline
\end{tabular}




\section{DISCUSSION}

The results of WEIMS and MWMS show that autonomous motivations drive the project team. In detail, Table 4 illustrates that both scales achieved a higher mean the closer the question got regarding the degree of autonomy. Interestingly, the extrinsic motivation of WEIMS was more highly rated than the extrinsic regulation in MWMS. Nevertheless, in both scales it lies between amotivation and introjected regulation. Also, the SD varies less on both ends of the scales (AM and Intrin), which means that there is clarity about what is important for the extreme case (see Tables 2 and 3), where a higher variance does exist within the continuum.

In combination with the W-BNS scale, it can be stated that the fulfilment of the three psychological needs is important to achieve autonomous motivation. As pointed out by Gagné et al. (2015), "autonomous types of motivation [are] positively related to the satisfaction of the psychological needs" (p. 191). Thus, the data corresponds with the SDT. Furthermore, the data of the WEIMS and MWMS demonstrates the importance of aligning goals, values, and regulations of the project delivery system with the individual and group goals, values, and regulations. Hence, according to Schöttle and Tillmann (2018), a process to define, set, and track goals should be installed to support collaboration. This means that more attention needs to be focused on the environment in which project teams interact as well as on the project team itself. As explained by Deci et al. (2017), the workplace context as well as the individual differences impact the psychological needs and thus the motivation. The creation of an environment that supports autonomy, competence, and relatedness is paramount. Project teams need the authority to decide what is best for their projects and therefore must be empowered by the strategic leadership of the various organizations. This requires the development of trust in and ownership by the project team. Thus, relatedness is key in the project delivery system, and therefore the demand for collaboration within the Lean community is correct. The traditional project delivery system is based on control and clashes with the autonomous motivation of project teams. By implementing a collaboration-enhancing environment, competence will be encouraged and can be fostered through transparent learning processes.

Table 4: Overall Mean (M) of MWMS and WEIMS

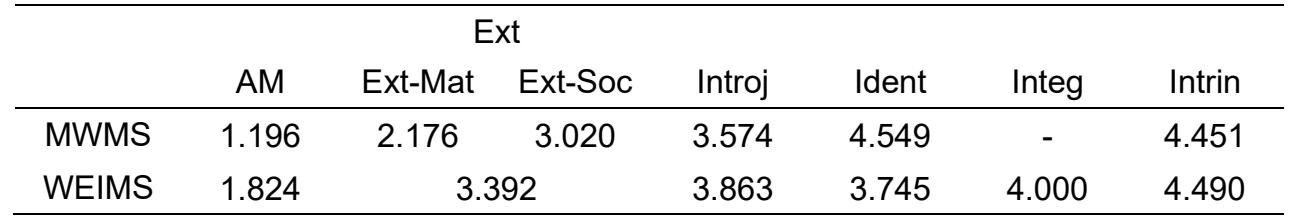

Another aspect of the data is the respondents' experience. Although there is a variance regarding their feelings about their current project, the motivation of the project team members is still autonomous. However, if there is no change regarding the environment and a decrease in frustration, demotivation that leads to a loss of performance could be the result.

\section{CONCLUSIONS}

The data indicates that the satisfaction of psychological needs drives the individual's motivation, and thus has an effect on the performance of the project team. Therefore, organizations must focus their attention on balancing and fulfilling those psychological 
needs within a project team by creating an environment that increases the autonomous motivation. Thus, the research question can be answered as follows: Project team members are driven by autonomous motivation. Based on the data, and by considering the sample size, the satisfaction with autonomy is very high. Therefore, the satisfaction of the psychological needs, the project setting, and the relationships among the team members are very important. Consequently, an environment is necessary that enhances autonomous motivation to drive the collaborative behavior of the project team. Nevertheless, more data is needed to validate the assumptions, because the study contains the following limitations: (1) idealization of the reference project, because of the time difference, (2) data relies on self-report, (3) personal preferences and differences in need satisfaction are not considered, (4) different impacts of each psychological need are not considered, (5) minor evaluation bias through impression management, and (6) the small sample size that was not randomly chosen. Furthermore, (7) the cultural background needs to be considered, and (8) there was no differentiation made between the design and construction team. Thus, more research is needed to represent the construction industry.

\section{ACKNOWLEDGMENTS}

The author wants to thank all the survey participants for taking the time to answer the questions.

\section{REFERENCES}

Broeck, A., Vansteenkiste, M., Witte, H., Soenens, B., and Lens, W. (2010). "Capturing autonomy, competence, and relatedness at work: Construction and initial validation of the Work-related Basic Need Satisfaction scale." Journal of Occupational and Organizational Psychology, 83(4), 981-1002.

Christensen, R., Greenhalgh, S., and Thomassen, A. O. (2019). "When a business case is not enough, motivation to work with lean." Proc. 27th Annual Conference of the International Group for Lean Construction, Dublin, 275-286.

Deci, E. L., Nezlek, J., and Sheinman, L. (1981). "Characteristics of the rewarder and intrinsic motivation of the rewardee." Journal of Personality and Social Psychology, 40(1), 1-10.

Deci, E. L., Olafsen, A. H., and Ryan, R. M. (2017). "Self-Determination Theory in Work Organizations: The State of a Science." Annual Review of Organizational Psychology and Organizational Behavior, 4(1), 19-43.

Deci, E. L., and Ryan, R. M. (1985). Intrinsic Motivation and Self-Determination in Human Behavior. New York, NY: Plenum Press.

Deci, E. L., and Ryan, R. M. (2000). "The 'what' and 'why' of goal pursuits: Human needs and the self-determination of behavior." Psychological Inquiry, 11(4), 227-268.

Deci, E. L., and Ryan, R. M. (2014). "The Importance of Universal Psychological Needs for Understanding Motivation in the Workplace." The Oxford Handbook of Work Engagement, Motivation, and Self-Determination Theory.

Fehr, E., and Falk, A. (2002). "Psychological foundations of incentives." European Economic Review, 46(4-5), 687-724.

Gagné, M., and Deci, E. L. (2005). "Self-determination theory and work motivation." Journal of Organizational Behavior, 26(4), 331-362.

Gagné, M., Forest, J., Vansteenkiste, M., Crevier-Braud, L., van den Broeck, A., Aspeli, A. K., Bellerose, J., Benabou, C., Chemolli, E., Güntert, S. T., Halvari, H., Indiyastuti, D. L., Johnson, P. A., Molstad, M. H., Naudin, M., Ndao, A., Olafsen, A. H., Roussel, 
P., Wang, Z., and Westbye, C. (2015). "The Multidimensional Work Motivation Scale: Validation evidence in seven languages and nine countries." European Journal of Work and Organizational Psychology, 24(2), 178-196.

Ryan, R. M., and Deci, E. L. (2000a). "Intrinsic and Extrinsic Motivations: Classic Definitions and New Directions." Contemporary Educational Psychology, 25(1), 5467.

Ryan, R. M., and Deci, E. L. (2000b). "Self-determination theory and the facilitation of intrinsic motivation, social development, and well-being." American Psychologist, 55(1), 68-78.

Ryan, R. M., and Deci, E. L. (2018). Self-determination theory: Basic psychological needs in motivation, development, and wellness. New York, NY: The Guilford Press.

Schöttle, A., Haghsheno, S., and Gehbauer, F. (2014). "Defining cooperation and collaboration in the context of lean construction." 22nd Annual Conference of the International Group for Lean Construction: Understanding and Improving Project Based Production, IGLC 2014.

Schöttle, A., and Nesensohn, C. (2019). "The Beauty of a Phase-Overlapping Last Planner System ${ }^{\circledR}$ With Incorporated Takt." Proc. 27th Annual Conference of the International Group for Lean Construction (IGLC), (July), 441-450.

Schöttle, A., and Tillmann, P. A. (2018). "Explaining the benefits of team goals to support collaboration." Proc. 26th Annual Conference of the International. Group for Lean Construction (IGLC), Chennai, India, 432-441.

Tremblay, M. A., Blanchard, C. M., Taylor, S., Pelletier, L. G., and Villeneuve, M. (2009). "Work Extrinsic and Intrinsic Motivation scale: its value for organizational psychology research.” Canadian Journal of Behavioural Science, 41(4), 213-226. 